\title{
Research on Innovation of Small and Micro Enterprises Financing Model Based on Cloud Services
}

\author{
Dao-hai Zhang ${ }^{1, a}$ and Miao-miao Fan $^{1, b}$ \\ ${ }^{1}$ School of Management, Jiangsu University, Zhenjiang 212013, China \\ azdh@ujs.edu.cn, ${ }^{\mathrm{b}} 570786102 @ q q . c o m$
}

Keywords: Cloud Services; Small and Micro Enterprises; Financing Model; Innovation

\begin{abstract}
Cloud computing, the background technology and capacity guarantee to Internet applications, has been widely and deeply used in recent years, which also gives small and micro enterprises a new way to solve the problem of financing. This paper analyzes the current situation of small and micro enterprises financing models in China and the existing problems, then proposes a new model of small and micro enterprises financing based on cloud services under the guidance of government, as to deal with the financing information asymmetry fundamentally and reduce the financing risks. Besides above, it puts forward the overall architecture and process of the small and micro enterprise financing model based on cloud services. Finally, it gives suggestion of development. This model integrates varies social resources, has the multilateral platform effect, uses big data in the cloud to improve transparency and instantaneity of financing information of small and micro enterprises and reduce the risk of the investor and network platform, which explores a new way for small and micro enterprises financing model platform to develop more open and better.
\end{abstract}

\section{Introduction}

China National Administration for Industry and Commerce small and micro enterprises development report (2015) shows that small and micro enterprises accounted for $76.57 \%$ of the total number of enterprises. The economy of small and micro enterprises plays an indispensable role in the development of the regional economic. In our country, the life expectancy of small micro enterprises is only 2.9 years, about $30 \%$ of small and micro enterprises go bankrupt each year. In the closure of enterprises, about $32 \%$ is due to funding issues[1]. In recent years, the Internet finance has explored a development path of inclusive financial with Chinese characteristics to solve the financing problems for small and micro enterprises. In particular, P2P provides a new channel for small and medium-sized enterprises to financing and investors to do financial management. However, the number of platform increases wildly, which leads to many chaos phenomena occur frequently, such as false targets, evade debt, nude loan, illegal storage and other risky events, which damage seriously to the interests of investors. This phenomenon has also become one of the new significant inducements for the occurrence of social mass disturbances and unstabilized factors. Therefore, it is necessary to review the financing innovation model of small and micro enterprises again, establish a more efficient operational mechanism, reduce investment risks and explore a new way for developing small and micro enterprises financing in a healthy environment.

\section{Review}

In the study of financing models of small and micro enterprises, scholars mainly focus on supply chain model, group lending model, industrial cluster model, Internet banking and other aspects. Leora Klapper analyzes the reverse guarantee mechanism used in supply chain management, and through the integration of production operations, financing for small and medium enterprises in the upper and lower reaches[2]. Subsequently, scholars have proposed various supply chain financial services innovation model[3] to provide financing needs for upstream and downstream enterprises, especially the core enterprises should play the role of big data in the supply chain. Varian research suggests that the 
self-selection and monitoring mechanism within the group helps to resolve mutual trust and effectively alleviate the financing difficulties caused by asymmetric information[4]. There is a strong correlation between industrial cluster network relationship and its competitiveness, Porter believes that financial institutions access to industrial cluster characteristics and information, can reduce the adverse selection problem caused by information asymmetry, and reduce the risk of financial credit[5]. With the development of Internet finance, the credit model of small and micro enterprises shows a trend of diversification, and various credit models emerge to meet the different characteristics of credit demand[6].

\section{The Current Situation and Problems of Small and Micro Enterprises Financing Model in China}

By conducting the way of questionnaire survey and deep interview to small and micro enterprises in Jiangsu and Zhejiang, it is found that China's small micro-enterprise financing model mainly includes bank loan financing, supply chain financing, B2C e-commerce platform financing, P2P platform financing and financial leasing.

\subsection{Bank loan Financing Model}

The survey shows that for most small and micro enterprises bank loan financing is still the preferred financing models. On one hand, take the cost of financing into consideration, $76.47 \%$ of small and micro enterprises believe that the cost of bank credit financing is more reasonable. Compared with private financing rates, bank credit financing is more cost-effective. It is the primary cause why small and micro enterprises would like to choose the way of bank loan financing. On the other hand, compared with the large bank, the procedure of small and medium-sized banks loan is simpler. 32.89\% of enterprises take small and medium-sized banks as the preferred choice, much higher than the $12.44 \%$ of the large bank. Regional joint-stock banks, local commercial banks and rural banks and other small and medium banks can summary potential information such as the personal information of the entrepreneur of small and micro enterprises and market condition of products to make a comprehensive analysis. It estimates the qualification of small and micro enterprises sufficiently and reduces the transaction cost to some extent[7].

Question: Small and micro enterprises have a strong willing to loan from banks, in practice, the difficulty in financing perplexes not only small and micro enterprises but also the banks. On one hand, small and micro enterprises operate with great uncertainty and high risks. On the other hand, under these existing financing models, the bank devotes almost the same number of staff and time into auditing the loan between small and-micro enterprises and medium-large enterprises. The cost is very high but the rate of return is relatively low.

\subsection{Supply Chain Financing Model}

Supply chain financing, namely integrating the capital flow into supply chain management. Small and micro businesses take receivable, inventory, prepayments as the collateral, the core enterprise provides a surety, such a way of applying for a loan from the financing institutions[8]. The operation conditions of the enterprise's upstream and downstream are taken into consideration as well, in order to increase credit for the enterprise when applying for a loan from the financing institutions. Once financial institutions support the enterprise, at the same time, it will also offer some discounts, depending on situations, for the upstream and downstream enterprises to encourage more small and micro enterprises to participate in.

Question: At the present stage, financial institutions usually introduce the third-party logistics to represent their management and control of collateral. In addition, it also carries out the field supervision to the business activities of credit enterprises. This is the key of financial institutions making a credit evaluation to enterprises in the supply chain. However, the third-party logistics enterprises, at present, lack the professional ability and the ability to integrate resources. In the process of information collection and collation, it could exist the risk of distortion in a higher degree, resulting in increased financing costs. 


\subsection{B2C E-commerce Platform Financing Model}

B2C is the abbreviation of Business-to-Customer. B2C e-commerce platform financing model is that e-commerce enterprises use their own platform, with the platform's online behavior data, to provide financing services for small and micro enterprises. According to the relationship between the supplier and the e-commerce platform, the present e-commerce platform financing can be divided into two categories: intermediary e-commerce platform financing model (such as Ali microfinance), mall e-commerce platform financing model (such as Jing dong Mall). The procedure is as follows: small and micro businesses apply for a loan; analyze and audit the historical transaction information, customers reviews, bank statements, product sales data in e-commerce platform of small and micro enterprises; provide a certain amount of loan for small and micro enterprises if approved; keep monitoring the operation of enterprises to control the risk after issuing the loan.

Question: Although the e-commerce platform has the "big data" of small and micro enterprises, it does not mean that credit risk can be reduced to zero. On one hand, with the continuous expansion of the size of loans, once credit default occurs, platform is likely to suffer huge losses because of the lack of collateral security. On the other hand, the funding gap are bigger and bigger, the platform providers (such as Alipay owned by Alibaba) have enormous number of precipitation funds, which in law can't be directly used in the loan business. How to make up for the gap in funding needs, which is also a realistic problem.

\subsection{Peer-to-peer Lending Platform Financing Model}

Peer-to-peer lending (the abbreviation is P2P) refers to the point-to-point financial lending behavior based on Internet platform. Foreign P2P platform is divided into two types: complex intermediary and pure intermediary. The former one shares the profit while taking risks, it not only provides trading platform but also acts as the guarantor, debt collector, interest rate constitutor and so on, investors take smaller risks (such as Zopa). The latter one does not share the benefits nor the risks in the course of the loan, it only provides platform but not get involved in the transaction. By matching the both side information to make a profit. The investment risk is borne by the lender, investors take larger risks (such as Prosper). The higher the risk, the higher the yield.

In 2007, P2P platforms rise in our country, "2016 P2P industry report" shows that the trading volume of P2P in 2016 has reached 2063.872 billion yuan. The number of investors and lenders increased by $134.64 \%$ and $207.37 \%$ respectively, compared with the year of 2015.Trillions of capital get into the P2P industry and the popularity is also increasing year by year. There are three kinds of modes: online unsecured model (such as Paipaidai), online+offline guaranteed model (such as Renrendai) and the third-party guarantee platform model (such as Renrenjucai). These models bring huge energy for the survival and development of small and micro enterprises[9].

Question: P2P in our country is still in its infancy, from the perspective of government, the regulations of $\mathrm{P} 2 \mathrm{P}$ are not sound, supervision is not effective and the credit can't be guaranteed. The number of platform increases wildly, which leads to many chaos phenomena occur, such as false subject, evade debt, illegal storage and other risky events occur frequently, which damage seriously to the interests of investors.

\subsection{Financial Leasing Financing Model}

Financial leasing is the lessor(investors) purchase equipment in accordance with the demand of the lessee(small and micro enterprises). During the lease term, the lessee only have the right to use but not the ownership. The ownership of the equipment belongs to the lessor. However, the lessee must pay the rent of using the equipment to the lessor by instalments in accordance with the contract signed by the two parties, bear the risk of daily maintenance and depreciation of the equipment. The lessee lease expires and decides to purchase, renew or return the equipment to the lessor.

Question: With the progress of the times, small and micro enterprises in some areas gradually formed its own industrial clusters and economic clusters after the continuous integration, which provides a huge market space for financial leasing. However, if there are some difficulties in corporate finances during the lease term, the fixed expenditure will become a heavy burden of the enterprise. In addition, the 
ownership of the leased assets belongs to the lessor, the lessee shall not be entitled to residual value of assets. Especially, when the residual value is large, it will cause great losses to the lessee after the expiration of the lease contract.

To sum up, by analyzing the current situation and problems of small and micro enterprises financing models, as we can see, these financing models are trying to increase the transparency of small and micro enterprises through a variety of ways, reduce the risk of financing, reduce barriers caused by asymmetric information. However, these models are not completely mature, there are still many problems to solve. The existing models can only topically ease the difficulties of small and micro enterprises financing, however, in order to solve the information asymmetry of both investor and financing party fundamentally and reduce the risk of financing, it still needs to explore a new way out.

\section{Construct a New Financing Model for Small and Micro Enterprises Based on Cloud Services}

"Internet $+"$ leads every industry to explore innovation, and cloud computing technology as the "Internet +" background technology and capacity guarantee, it has been rapid development in recent years, the application has matured. The relevant ideas(such as resource integration, platform, big data, credit rating, small dispersion, etc.) applied in the existing financing model also provide us very valuable ideas. The core idea of cloud service is based on cloud computing and big data technology to construct transparent communication between cloud subjects. Therefore, standing in the Internet environment, this paper builds a new model of small and micro enterprise financing based on cloud service on the basis of existing financing models and technology. It is based on the idea of the cloud services platform to put forward a new more effective financing channel.

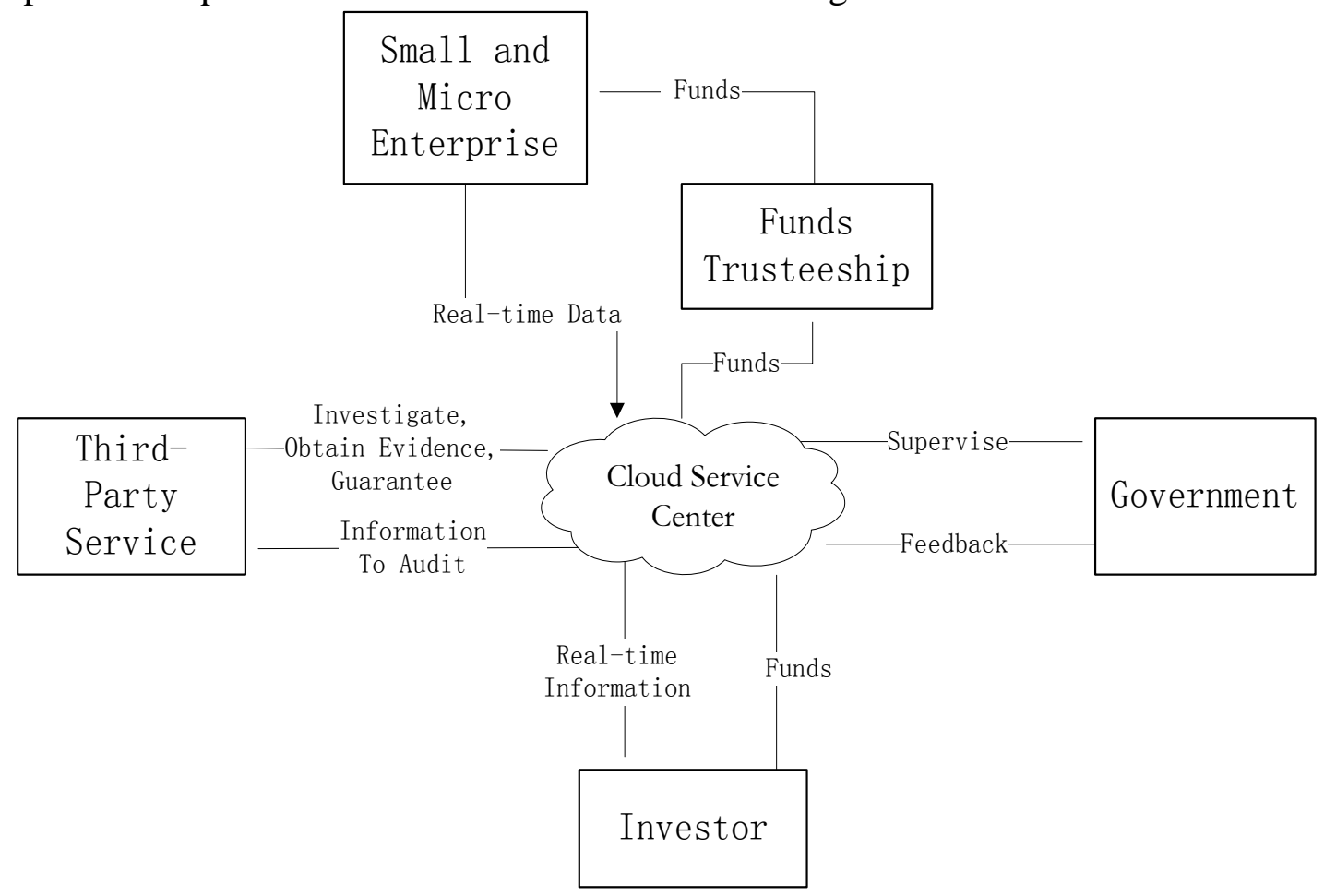

Figure.1. Small and Micro Financing Model Framework Based on Cloud Services

The overall model structure shown in Figure 1, cloud service platform is a government-led multi-party social capital and the main body of the financial innovation service model, which is conducive to the government financial institutions, small loan companies, insurance companies, third parties Service agencies and other resource integration, and promote the exchange of information between these entities and integration. The borrower uses the cloud service platform to issue a loan demand, and the investor uses the cloud service platform to find the appropriate lender to issue funds. This transaction is largely depend on the transparency information of small micro-enterprises, such as borrowing purposes, credit levels and actual financial information, how to ensure the authenticity of such information, and reduce the risk of lenders, which requires a third party Service agencies, such as 
security agencies, insurance agencies, assessment agencies, etc. And how to investigate, certification, assessment and security, etc. in the whole process, which need government to supervise and create a good investment and financing environment, then may achieve multi-party win-win, so as to promote the coordinate development of all parties.

The whole process of financing as shown in Figure 2 in this mode: (1)Small micro-enterprises publish the demand for borrowing, usage, technological innovation and other related information in the cloud service platform. (2)Cloud service center requires third party service providers to provide small and micro enterprise information authentication, evaluation, credit, intellectual property, insurance and other services. (3)Third party service feedback to the platform. (4)Cloud service platform carry out pushing services according to the amount of borrowing of small micro-enterprises, enterprise business scale and credit level. (5)Investors in accordance with the borrower's demand information, and third-party service agencies to provide certification, assessment, credit, intellectual property, insurance and other big data comprehensive information to make investment decisions. (6)investing funds are credited to third parties in financial institutions. (7) Small micro enterprises obtain financing, and return the principal and interest within the time limit.

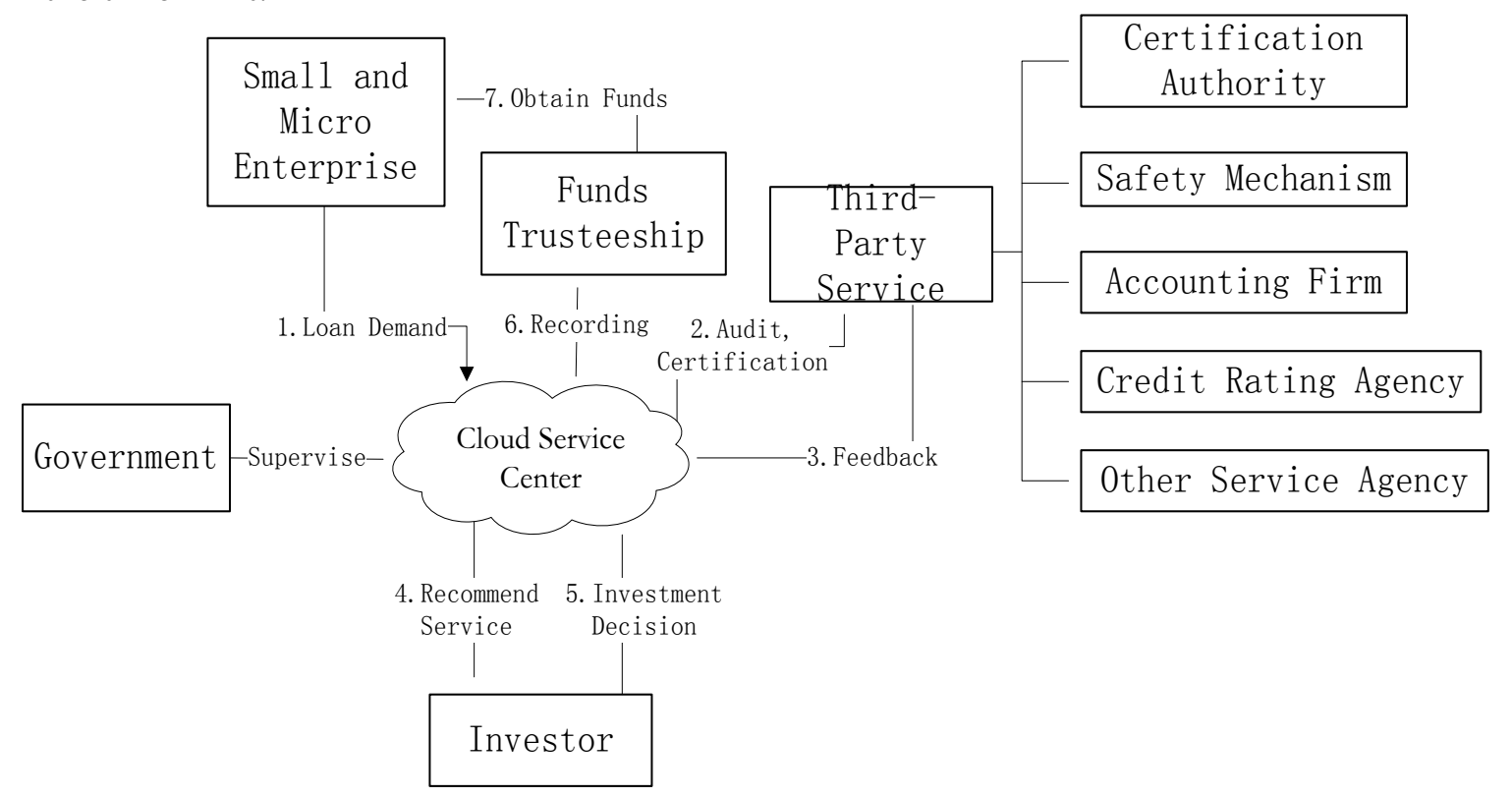

Figure.2. Flow Chart of Small and Micro Financing Model Based on Cloud Services

\section{Suggestion of Small and Micro Enterprises Financing Model Based on Cloud Services}

Small micro-enterprise financing mode which is based on cloud services can largely ease the asymmetry of small micro-enterprise information. From the efficiency point of view, this kind of mode has the characteristics of high efficiency and low cost. From the technical point of view, using cloud computing, big data and other modern information technology to build a small micro-enterprise comprehensive credit database for investors. And it can push personalized products and services, which can effectively reduce the investment risk. Seeing from the operating model, it based on government-led, integrated multi-party social resources, to achieve a win-win business model of the relevant subject. The development recommendations are as follows.

\subsection{Government-led "Top Leadership Project"}

In order to achieve the integration of multi-party social subjects, government coordination is very important. The government should vigorously encourage and effectively guide the social capitals and resources to take part in the small micro-enterprise financing environmental development, and effectively serve the small micro-enterprises. Meanwhile, the government should do a good job in the main body of the qualifications, and it should strictly review the borrower's qualifications, investors, sources of funds and admittance conditions to make a serious review and regulations, and monitor and 
supervise the funds well to create a harmonious healthy financing atmosphere, stop the "shadow bank" and the emergence of usury. Additionally, revising and improving the "Bankruptcy Law", "Loan General" and so on, which make small micro-enterprises' loans have laws to abide, or when appearing special problems, it can protect the interests of every party's main profits.

\subsection{Actively Amplify the Effects of Platform Networks}

The financing platform based on cloud services possesses the characteristics of open, democratic, and typical multilateral platform effect, which are shown that end users make trades and influences on each other on the platform. In addition, there exists relatively prominent crossing-network effects among various end customers. This kind of effect can be effectively achieved through the platform services. Due to increasing small and micro enterprises gathered on the platform, social capital and subject resources are more likely to be invested, therefore, significantly reducing and spreading the risks of investments.

\subsection{Enhance Communications and Interactions among Subjects}

The model of cloud service based financing is a multi-agent interaction model. For those small and micro enterprise, it is a self-adapting system. The more actively small and micro enterprises interact with other subjects, the more it is able to enhance their activity in the platform. Furthermore, big data's real-time exchange data acts as the basement of reinforcing the credits of an enterprise.

\subsection{Perfect Third-Party Service System}

The model of cloud-service-based financing is capable of driving business innovation of third-party service agency such as guarantee model. When a guarantee institution gains some basic understandings on the growing trends and qualifications of enterprises, it is able to recommend excellent enterprises or projects to the investors, which not only highly improving efficiency, but also remarkably cutting down the high costs and risky possibilities. Moreover, guarantee institutions can utilize the data integration of credits assessment, assets appraisal, and financing assurances to form an operation mode that takes the guarantee of financing as the main activity, supplemented by credit and assets evaluation. Under the context of Internet era, third-party service are certain to create more applicable and efficient intermediary service models, with the internet+ mindset, to play a key role in supporting of good operations in the financing businesses.

\section{Acknowledgement}

In this paper, the research was sponsored by Chinese National Natural Science Foundation(Project No. 71471076) and Chinese Postdoctoral Science Foundation(Project No. 2015M581749) and Jiangsu Province Social Science Foundation (Project No. 13JDB031) and Jiangsu University Senior Talent Foundation(Project No. 15JDG007).

\section{References}

[1] Zhang Lianqi, Liu Jian,Guo Ting. Research on Small and Micro Enterprise Financing Model Based on E-commerce Platform[J]. China Business and Market, 2014, 08:49-54.

[2] Leora Klapper. The Role of Reverse Factoring in Supplier Financing of Small and Medium Sized Enterprises[J]. World Bank, 2004, 09:89-100.

[3] Jiang Chaofeng. Supply Chain Financial Service Innovation[J]. China Circulation Economy, 2015,01:64-67.

[4] Varian,Hal R. Monitoring Agents with Other Agents[J]. Journal of Institutional Theoretical Economics, 1990,146: 153-174.

[5] Michael E Porter. Clusters and New Economics of Competition[J]. Harvard Business Review, 1998,11:91-99. 
[6] Hui Wei. Search for the Direction of Internet Finance Research in China[J]. Journal of Northwestern University, 2015,45 (4): 44-50.

[7] Chen Wen, Wang Fei. Network Lending and SME Financing[M]. Bei Jing: Economic Management Press, 2014.

[8] Tang Lili. An Extended Study on the Financing Mode of Enterprises Based on Supply Chain Financing[J]. Times Finance, 2014,20:171-172.

[9] Gu Xiujuan, Zhang Xiajing. A Study of Innovation in Financing Mode for Small \& Micro Enterprises Based on Internet Banking[J]. Journal of Henan University of Technology(Social Science Edition), 2015,11(3):101-104. 